\title{
Kommentteja Outi Vuorenrinteelle
}

\author{
Pirjo Tuomi \\ Oulun yliopisto \\ ptuomi09@gmail.com
}

Pirjo Tuomen kommentteja Outi Vuorenrinteelle koskien Vuorenrinteen väitöskirjaa.

Asiasanat: kirjastoala; kirjastohistoria; yleiset kirjastot; Helle Kannila; kaunokirjallisuus; viihdekirjallisuus; lukuharrastus

Aluksi pahoittelen Vuorenrinteen väitöskirjan puuttumista oman väitöskirjani lähdeluettelosta, mikä on tietysti anteeksiantamatonta huolimattomuutta minulta. Viittaus "freudilaiseen lapsukseen" kuulostaa tosin liioitellulta. Kun Vuorenrinteen väitöskirja tuli julki oman väitöskirjatyöprosessini aikana, on kai luonnollista, että tutustuin siihen ja huomioin siinä esiin tulleita seikkoja niiltä osin kuin ne liittyvät oman väitöskirjani aihepiiriin.

Kuten väitöskirjani johdannossa totean, väitöskirjaani ovat omalla tavallaan motivoineet kysymykset: "Voiko kyseenalaistamalla tiettyjä yhteisiä ymmärryksiä ja tulkintoja tuottaa toisenlaisia tulkintoja ja näkemyksiä? Voiko todellisuuden haastaa uusilla näkökulmilla, kun reflektoidaan sitä todellisuutta, joka saatavilla olevista dokumenteista avautuu? Tässä tutkimuksessa pyritään ymmärtämään ja tulkitsemaan - paikoin kriittisestikin - sekä mennyttä että nykyistä todellisuutta.” Vuorenrinne itsekin vastineessaan huomauttaa, että historiantutkimus on "alati elävää ja kehittyvää ja uusille tulkinnoille avointa tietämyksen ja ymmärryksen lisääntyessä, 
niin myös kirjastohistorian tutkimus". En ole historiantutkija enkä näin ollen pidä omaa väitöskirjaanikaan historiantutkimuksena, mutta eräänlaisena historiallisesti taustoitettuna kirjallisuussosiologisena kirjastotutkimuksena kylläkin.

Kun toisaalta omassa väitöskirjassani on keskeisenä ollut pyrkimys hahmottaa kaunokirjallisuuden asemaa yleisessä kirjastossa eri aikoina, on huomioitava sitä luettaessa - kuten sen johdannossa huomautankin - että "esimerkiksi erilaiset merkittävät suomalaisen kirjastohistorian käännekohdat ja niiden tulkinnat saattavat näyttäytyä toisenlaisina kuin jos halutaan vastauksia muunlaisiin institutionaalisiin kysymyksiin". Esimerkiksi Vuorenrinne omassa väitöskirjassaan etsii vastauksia toisenlaisiin kysymyksiin, joten hänen tulkintansakin voivat olla toisenlaisia kuin omani, vaikka aihepiiri on osittain yhteinen.

Mitä tulee Vuorenrinteen kommenttiin siitä, että hän on kokenut minun pyrkineen "mitätöimään" hänen väitöskirjansa aiheen, olen todella pahoillani, jos hän on ymmärtänyt asian näin. Pidän Outi Vuorenrinteen väitöskirjaa merkittävänä lisänä vähälukuisessa suomalaisessa kirjastotutkimuksen kentässä. Meillä voi tosin olla tiettyjä tarkastelukonteksteistakin johtuvia näkemyseroja siitä, miten 1960-1970luvuilla ns. hyvinvointivaltion rakentamisen myötä alkanut, itse institutionaaliseksi muutokseksi kutsumani kirjastolaitoksen uudelleen määrittely on vaikuttanut kirjaston myöhempään kehitykseen ja pitäisikö tuo kehitys nähdä pelkästään positiivisena. Vuorenrinne rinnastaa kirjastolaitoksen muutoksen koululaitoksessa / kansansivistystyössä tapahtuneisiin muutoksiin sekä populaarikulttuurin nousuun. Itse tarkastelen tapahtuneita muutoksia ensisijaisesti kulttuuri- ja taidepoliittisen tutkimuksen hahmottamassa kontekstissa, koska näen kirjaston ennen muuta kulttuurilaitoksena ja kaunokirjallisuuden yhtenä taiteen alalajina.

Kuvaan väitöskirjassani kirjastolaitoksemme alkuvuosikymmenien (noin 1920luvulta 1960-luvulle) kehitystä muutoksena "valistuskirjastosta lukijan kirjastoksi", millä tarkoitan sitä, että lukijoiden vähitellen löytäessä kirjastot kaunokirjallisuuden määrä kokoelmissa lisääntyi ja monipuolistui. Vuorenrinteen näkemyksen mukaan keskeistä on kirjastolaitoksen muuttuminen "sivistyskirjastosta palvelulaitoskirjastoksi”. Muutos alkoi 1960-1970-luvuilla. Oman tutkimusaineistoni ja lähdekirjallisuuteni (ks. esim. Buschman, 2003; D’Angelo, 2006; McMenemy, 2009; Vestheim, 2009) pohjalta minulle syntyi näkemys, että kun kulttuurilaitoksiin, ja myös kirjastoon, tuotiin liike-elämän mallin mukainen palvelu- tai asiakaslähtöisyyttä korostavaa toimintakulttuuri, se mahdollisesti sivuutti muut instituution omaan identiteettiin ja toimintakulttuuriin liittyvät seikat. Tämä ajoittuu korostetusti uusliberalismin läpimurtoon 1990-2000-luvuille, mutta sen tiettyjä piirteitä oli näkyvissä jo 1960-1970-luvuilla. Tuon väitöskirjassani esille useita seikkoja, jotka perustelevat, miksi tämä kehitys ei välttämättä ole ollut pelkästään myönteistä kirjaston ja muiden kulttuurilaistosten kannalta.

Vaikka sekä Vuorenrinne että minä omissa väitöskirjoissamme pohdimme Hel- 
le Kannilan kirjallisuusnäkemyksiä ja hänen valintapoliittisiin kriteereihinsä liittyviä kysymyksiä, voivat aivan perusteltavissa olevat tulkinnat Kannilan kirjoituksista mielestäni ihan perusteltavissa olevin tavoin poiketa toisistaan. Se miten lähteitä tulkitaan ja mitä lähteitä valitaan on tutkijan kannalta aina myös subjektiivista. On myös huomioitava kuten väitöskirjassani totean, että Kannilan lukuisissa teksteissä on paljon monitulkintaisuutta ja ristiriitaisuuttakin, ja sekä hänen ajatuksensa että kirjoituksensa muuttuivat kirjastoinstituution kehityksen myötä (ks. esim. Tuomi, 2017, ss. 138-139) . Väitöskirjassani pyrin esimerkiksi instituutio- ja kulttuuripolitiittisen tutkimusperinteen pohjalta selittämään, miksi Kannilan uran arvioinnissa on huomioitava hänen asemansa instituution rakentajana ja toisaalta ne yhteiskunnalliset ja kulttuuriset haasteet ja olosuhteet, joissa hän työskenteli. Kirjastoinstituution rakentajat niin Suomessa kuin esimerkiksi Yhdysvalloissa (josta väitöskirjassani on runsaasti vertalevaa aineistoa) tekivät legitimiteetin saavuttamiseksi kompromisseja myös kirjavalinnan kysymyksissä toisaalta kirjastonkäyttäjien toiveiden ja toisaalta esimerkiksi valtaapitäviä edustavan kirjallisen eliitin vaatimusten välillä. Myös kirjastolaitoksen toimintaa rajoittavat taloudelliset realiteetit asettivat omat reunaehtonsa.

Kun väitöskirjassani huomautan, että esimerkiksi Vuorenrinne ei tarkemmin määrittele, mitä tarkottaa Kannilan syrjimällä viihdekirjallisuudella, en viittaa Niemen ja Kannilan viihdekirjallisuuskäsitysten yhteneväisyyteen, vaan mainitussa kohdassa (Tuomi, 2017, s. 133) aikaisemmin esitettyyn Kannilan omaan määrittelyyn. (Huomautan tosin, että "esimerkiksi Niemen populaarikirjallisuuden ja Kannilan viihdekirjallisuuden määrittelyistä voidaan löytää samoja elementtejä: kaupalliset tavoitteet, eli pyrkimys mahdollisimman suuren lukijakuntaan tavoittamiseen sekä sisällöllisen jännityksen ja tietynlaisen romanttisen eskapismin tarjoaminen lukijalle" (Tuomi, 2017, s. 133.) Kannila näkee viihdekirjallisuuden jakautuneena eri alalajeihin ja toisaalta käyttää laatukriteereitä puhuen "heikomman tason viihdekirjallisuudesta" tai "huonosta viihdekirjallisuudesta" ja arvottaa myös alalajeja näillä kriteereillä. Hän tuomitsee "huonon" ja "ala-arvoisen" viihdekirjallisuuden ("roskakirjallisuuden") ainakin kirjastoihin tarpeettomina hankintoina. Hän korostaa myös, että "viihdekirjallisuus jos mikä jakautuu omassa lajissaan moneen eritasoiseen ryhmään, joukossa on sekä onnistunutta että epäonnistunutta viihdettä." (Esim. Kannila, 1967, ss. 94-135). Väitöskirjassani tuon myös mielestäni perustellusti esille näkemyksiä, että kirjastonhoitajan ammatilliseen osaamiseen liittyy kyky tunnistaa erityyppistä kirjallisuutta. Huomautettakoon myös, että ymmärtääkseni koskaan Kannilan jälkeenkään kirjastoihin ei ole hankittu ns. kevyttä kioskikirjallisuutta! Lukijatutkimuksetkin (esim. Eskola, 1979, 1990; Niemi, 1975) osoittavat, että sen tyyppinen kirjallisuus ostetaan kioskeista.

Varhaisista kirjavalintakysymyksistä tai Helle Kannilan elitistisestä ja paternalistisesta suhtautumisesta kirjastonkäyttäjiin ja lukijoihin meillä on vallinnut joten- 
kin yksimielinen ja yksipuolinen käsitys, joka ainakin aiheeseen liittyviä graduja ja ja muita opinnäyteitä lukiessa on hyvin paljon perustunut 1973 ilmestyneeseen Lainakirja-nimisen pamflettimaisen julkaisun artikkeleihin tai lähteisiin, joissa käsitellään muun muassa "Polva-Golon-Muskett -valtionapujupakan" tyyppisia tapahtumia. Esimerkiksi Hilkka M. Kaupin kirjoittama pieni elämäkerta Helle Kannilan elämänpuut tuo esille monipuolisesti Kannilan ajattelua. Tässä elämänkerrassaan Kauppi muun muassa avaa mielenkiintoisella tavalla Kannilan suhdetta sukupuolten tasa-arvoon liittyviin kysymyksiin mainiten Kannilan usein toistaneen: "Ei olla miehiä eikä naisia vaan kansalaisia" (Kauppi, 1976, s. 89). Kannila ajoi aikanaan voimakkaasti myös esimerkiksi miesten ja naisten samapalkkaisuutta. Hän toimi jo 1900-luvun alkupuolelta lähtien aktiivisesti naisliikkeessä, ja tähän osaltaan saattoi liittyä myös hänen vieroksuva suhtautumisensa kevyeen, naisille tarkoitettuun viihdekirjallisuuteen, kuten väitöskirjassanikin totean (Tuomi, 2017, s. 128). Väitöskirjassani kritisoin myös sitä, että Kannilan teksteistä on otettu joitakin jopa asiayhteydestään irroitettuja sitaatteja, joita on sitten toisteltu eri yhteyksissä Kannilan kirjallisuus- ja kirjastopoliittisten näkemysten ilmentäjinä (ks. esim. Tuomi, 2017, ss. 127, 139). Huomautettakoon vielä, että en millään tavoin halua kuitenkaan väheksyä Vuorenrinteen väitöskirjassaan käsittelemää Kannila-aineistoa.

Kun oman väitöskirjani aiheena oli kartoittaa kirjastolaitoksen ja kaunokirjallisuuden suhteen kehittymistä, hieman tietoisestikin pyrin irroittautumaan kaikenlaisista "stereotypioista" ja katsomaan mahdollisesti niiden taaksekin. Halusin selvittää, oliko Kannilan kirjallisuuskäsitys yksiselitteisen elitistinen ja kaikkea viihdekirjallisuutta syrjivä. Mielestäni olen kyennyt esittämään omille, vaihtoehtoisille näkemykselleni vankastikin näyttöä, vaikka Vuorenrinne näkeekin asian toisin.

Lopuksi haluan nostaa esille vielä kysymyksen lukuharrastuksesta, jota käsittelen väitöskirjassani laajemmin. Yleisen kirjaston tavoitteena on ollut lukuharrastuksen tukeminen ja on edelleenkin myös kirjastolain mukaan. Se ei ymmärtäkseni voi tarkoittaa sitä, että kirjastossa on vain saatavilla erilaista kirjallisuutta kuten vaikkapa kirjakaupoissa, vaan paljon laajempaa, paitsi lukuharrastuksen myös yleisemmin kirjallisuuden eteen tehtävää työtä. Se tarkoittaa myös sitä, että kirjaston tehtävänä on puhua kirjallisuuden puolesta ja kaunokirjallisuuden puolesta yhtenä taiteen lajina. Voi olla, että aikaisemmin kirjallisuuden puolesta puhuminen motivoi voimakkaammin kirjastoammatillista työtä, mutta olen vakuuttunut, että tänäkin päivänä kirjastoissa tehdään kaunokirjallisuustyötä ajatuksella, että lukeminen liittyy sivistykseen ja ihmisen henkiseen kasvuun. Tämän tahtoisin ajatella kuuluvan kirjastonhoitajuuteen tulevaisuudessakin, mikä olisi myös Kannilalta löydettävissä olevan vahvan eetoksen mukaista.

Turengissa 20.11.2017

Pirjo Tuomi 


\section{Lähteet}

Buschman, J. (2003). Dismantling the Public Sphere: Situating and Sustaining Librarianship in the Age of the New Public Philosophy. Westport, Connecticut \& London: Libraries Unlimited.

D'Angelo, E. (2006). Barbarians at the Gates of the Public Library: How Postmodern Consumer Capitalism Threatens Democracy, Civil Education and the Public Good. Duluth: Library Juice Press.

Eskola, K. (1979). Suomalaiset kirjanlukijoina. Helsinki: Tammi.

Eskola, K. (1990). Lukijoiden kirjallisuus Sinuhesta Sonja O:hon. Helsinki: Tammi.

Kannila, H. (1967). Kirjanvalinnan ongelmia : ajatustenaiheita kirjastonhoitajille ja muille kirjojen ystäville. Helsinki: WSOY.

Kauppi, H. M. (1976). Helle Kannilan elämänpuut. Helsinki: Suomen kirjastoseura.

McMenemy, D. (2009). Telling a true story or making it up: Discourse on the effectiveness of the bookshop model for public libraries. Library Review, 58(1), 5-9. https://oadoi.org/10.1108/ 00242530910928889

Niemi, J. (1975). Populaarikirjallisuus Suomessa : huokean viihdekirjallisuuden osakulttuurin erittelyä. Porvoo: WSOY.

Tuomi, P. (2017). Kaunokirjallisuus suomalaiselle yleiselle kirjastolle haasteena, rasitteena ja mahdollisuutena: historiallis-argumentatiivinen tarkastelu suomalaisen yleisen kirjastolaitoksen suhteesta kaunokirjallisuuteen ja kirjalliseen järjestelmään. Oulu: Oulun yliopisto. http://urn.fi/urn:isbn: 9789526215389 (luettu 30.12.2017)

Vestheim, G. (2009). The autonomy of culture and the arts - from the early bourgeois era to late modern "runaway world". Teoksessa M. Pyykkönen, N. Simanainen, \& S. Sokka (toim.), What about Cultural Policy? Interdisciplinary Perspectives on Culture (ss. 31-53). Jyväskylä: Minerva. http://urn.fi/URN: ISBN:978-952-492-320-0 (luettu 18.12.2017) 